\title{
Las soluciones constructivas en la vivienda durante el franquismo: el caso de la vivienda ferroviaria
}

\section{Housing constructive solutions during Francoism: The case of railway housing}

\author{
$\underline{\text { A. Martínez-Corral }}^{(*)}$, D. Cuéllar ${ }^{(* *)}$
}

\section{RESUMEN}

La construcción de vivienda ferroviaria durante el franquismo, primero por parte de RENFE y luego a través de las cooperativas de ferroviarios, fue muy significativa totalizando unas veinte mil viviendas en el periodo 1945-1975. Al tratarse de viviendas promovidas por una empresa pública del franquismo se observa un condicionamiento particular en la tipología, la materialidad y la construcción; no sólo debido a la imposición de la ideología del Régimen sino también a las rígidas normativas y a los problemas de suministro y restricción de los materiales. El gran número de vivienda construida permitió la generalización de soluciones constructivas ya obsoletas y ayudó a consolidar a la mal denominada "construcción tradicional", alejándose de toda la innovación y experimentación previas en un patrimonio todavía en uso donde las arcaicas soluciones constructivas empleadas dificultan su adaptación sostenible tanto a las nuevas formas de habitar como a las actuales exigencias normativas.

Palabras clave: Vivienda social, construcción, materiales, patrimonio ferroviario, franquismo, autarquía.

\section{ABSTRACT}

The construction of railway housing during the Francoism, first by RENFE and then by railway cooperatives, was very significant with the construction of almost twenty thousand houses within 1945 and 1975. To be built by a Francoism company or by its employees determine typology, materiality and construction, not only due to the imposition of the regime's ideology but also to the rigid regulations and to the problems of supply and restriction of building materials. The large number of housing built allowed the generalization of obsolete building solutions and helped to consolidate the so-called "traditional construction" far away from all previous constructive innovation in a heritage still in use in which the constructive solutions employed hinder its sustainable adaptation to the new ways of living and the current normative demands.

Keywords: Social housing, construction, building materials, railway heritage, francoism, autarky.

(*) Doctora arquitecta. Profesora asociada. Universidad Politécnica de Valencia, Valencia (España).

$(* *)$ Doctor en Historia y Especialista en transportes terrestres. Grupo RENFE y Universidad Rey Juan Carlos, Madrid (España).

Persona de contacto: aumarcor@csa.upv.es (A. Martínez-Corral).

ORCID: https://orcid.org/oooo-ooo1-8222-0864 (A. Martínez-Corral); https://orcid.org/oooo-0002-1720-8575

(D. Cuéllar).

Cómo citar este artículo/Citation: Martínez-Corral, A.; Cuéllar, D. (2020). Las soluciones constructivas en la vivienda durante el franquismo: el caso de la vivienda ferroviaria. Informes de la Construcción, 72(558): e341. https://doi.org/10.3989/ic.71047.

Copyright: (c) 2020 CSIC. Este es un artículo de acceso abierto distribuido bajo los términos de la licencia de uso y distribución Creative Commons Reconocimiento 4.o Internacional (CC BY 4.0). 


\section{INTRODUCCIÓN: MARCO HISTÓRICO Y LEGISLATIVO}

La escasez de vivienda para la clase obrera ha sido uno de los grandes problemas a los que se enfrentó la sociedad española a mediados del siglo XX. En las primeras décadas del siglo, la situación se había agravado debido al creciente proceso de emigración del campo a la ciudad y a la falta de iniciativa en la construcción de nuevas viviendas, debido al escaso interés que ofrecía a los promotores por su baja rentabilidad (1).

El problema de la vivienda, así, adquirió a partir de la década de 1940 dimensiones de crisis y amenazaba con afectar la estabilidad del régimen franquista (2). De hecho, entre las primeras medidas legislativas del franquismo se encuentra precisamente la nueva legislación sobre vivienda. En concreto, la Ley de 19 de abril de 1939 tenía dos objetivos claros: primero, medidas de protección para incentivar la construcción de viviendas protegidas; $y$, segundo, la creación de un departamento regulador como el Instituto Nacional de la Vivienda (3).

En el primer caso, esta norma definía la vivienda protegida como aquella edificación que estaba incluida en los planes oficiales y cumplía con las normas mínimas de habitabilidad. La práctica totalidad de estas viviendas se destinaban al alquiler, y en el reglamento de la ley de 8 de septiembre se establecía que el alquiler no podía ser superior al importe de seis días de jornal o el 20\% del sueldo mensual del inquilino. Por último, se fijaban quiénes podían ser promotores: ayuntamientos, sindicatos, organizaciones del Movimiento, empresas, sociedades benéficas, cooperativas de propietarios y particulares para la construcción de su propia vivienda.

Para estimular este proceso, se establecían exenciones tributarias, préstamos sin interés, primas a la construcción y derecho de expropiación forzosa por causa de interés general público. La calificación definitiva de vivienda protegida para poder ser habitada se otorgaba una vez terminada la construcción y se verificara que se ajustaba al proyecto.

El segundo referente era la creación del Instituto Nacional de la Vivienda (INV), que nacía como un órgano dependiente directamente del ministro de Organización y Acción Sindical, posteriormente Ministerio de Trabajo. Entre sus atribuciones estaban: dictar ordenanzas de la construcción de viviendas protegidas, formular los planes generales de construcción, el reparto anual de anticipos y primas, proponer los tipos de modelo de viviendas, fijar el precio máximo de las viviendas y de los alquileres autorizados, aprobar los proyectos de construcción y las obras de urbanización, intervenir cerca de las cajas de ahorros y del Instituto Nacional de Previsión en las condiciones de financiación, aprobar los pliegos de condiciones, aprobar los presupuestos, y otras.
La ley de 1939 estuvo vigente durante tres lustros y reguló la promoción de viviendas durante la autarquía con gran escasez de recursos y materiales, y una sobreplanificación que hacía imposible el cumplimiento de los objetivos. Después, con los nuevos aires económicos, la ley de 15 de julio de 1954 sobre viviendas de renta limitada derogó la ley de 1939, junto a otras como la ley de viviendas bonificables de 25 de noviembre de 1944 y los decretos ley de 19 de noviembre de 1948 y 27 de noviembre de 1953 .

En la ley de 1954 se hacía un reconocimiento al papel jugado por la anterior ley y se daba un paso más en la liberalización del sector para apoyar las iniciativas particulares, mediante la elaboración de un plan general, la simplificación de los trámites administrativos, el aumento de los beneficios fiscales y la mejora en el sistema de financiación de los proyectos. Para facilitar la construcción de las nuevas viviendas, ahora denominadas de renta limitada, se establecía una clasificación que distinguía aquellas que solicitaban auxilios económicos del Estado de las que no, y las dimensiones máximas y mínimas de las mismas según un baremo oficial de precios (tabla 1) (4).

En este marco, es en el que RENFE y otras empresas públicas y privadas comenzaron un amplio programa de construcción de viviendas en alquiler para sus trabajadores $(5,6)$. Estos programas de las empresas se iniciaron con la ley de 1939, aunque la mayor parte de ellos no se llevaron a cabo hasta las décadas de 1950 y 1960, cuando también se extendieron las iniciativas de carácter cooperativo, también con fuerte presencia del colectivo ferroviario (7). En total, hemos contabilizado hasta el momento más de 7.000 viviendas construidas por RENFE en el periodo 1949-1971, algo más de 3.000 construidas por otras empresas del sector ferroviario, y más de 10.00o viviendas de origen cooperativo. La documentación consultada se encuentra en el Archivo del Ministerio de Fomento, en el Archivo Histórico Ferroviario y en varios archivos municipales.

\section{EL PROCEDIMIENTO ADMINISTRATIVO PARA LA CONSTRUCCIÓN}

RENFE obtuvo la consideración de "entidad constructora" de viviendas protegidas por Decreto de 26 de abril de 1944 (8). Ello la habilitaba para tutelar expedientes que se promovieran ante el INV y permitía que la empresa sólo tuviera que aportar como máximo el 10\% del presupuesto o, como alternativa, que se admitiesen a cuenta del mismo los solares de su propiedad donde iban a construirse las viviendas, que fue la opción más común, dada la disposición de suelo que tenía la compañía (9) ${ }^{1}$. También, al obtener esta consi-

Tabla 1. Clasificación de las viviendas de renta limitada según la ley de 1954.

\begin{tabular}{|l|c|c|c|c|}
\hline & Primer grupo & \multicolumn{3}{|c|}{ Segundo grupo } \\
\hline \multirow{2}{*}{ Categorías } & Sin ayudas públicas & \multicolumn{3}{|c|}{ Con ayudas públicas } \\
\cline { 2 - 5 } & & $1^{\text {a }}$ categoría & $2^{\text {a }}$ categoría & $3^{\text {a }}$ categoría \\
\hline Superficies & - & $80-200 \mathrm{~m}^{2}$ & $65^{-150 \mathrm{~m}^{2}}$ & $50-80 \mathrm{~m}^{2}$ \\
\hline Costes de ejecución & - & $<125 \%$ del módulo* & $75-100 \%$ del módulo* & $75 \%$ del módulo* \\
\hline
\end{tabular}

\footnotetext{
* El valor del módulo era una cantidad revisada periódicamente por el Ministerio.
}

\footnotetext{
${ }^{1} \mathrm{Al}$ respecto, véase la aportación sobre la gestión que hacía del suelo desafecto de uso ferroviario la empresa RENFE, en el texto de L. Santos.
} 
deración, RENFE podía ser beneficiaria de los préstamos al interés legal establecido (en torno al $3 \%$ ) y por un plazo de 20 años que otorgaba el INV. Las viviendas construidas eran propiedad del Estado y los proyectos y condiciones técnicas de las construcciones eran reguladas por el Ministerio de Obras Públicas.

La tramitación se iniciaba ante el INV con la solicitud para construir en una determinada parcela, donde se acreditaba la idoneidad de los terrenos mediante la justificación urbanística de los mismos (10). Estos, normalmente, se encontraban cercanos a una estación o enclave ferroviario. Ello conllevaba el aporte de escrituras demostrando la titularidad, así como la existencia de posibles cargas y la tramitación del preceptivo expediente de cesión de los terrenos a favor del INV. Una vez conseguida la autorización para construir y la cesión de los terrenos, se presentaba un anteproyecto y una breve memoria que detallaba previsión de ocupantes, valoración de los terrenos, plazo de ejecución y presupuesto, así como aportaciones y beneficios que se solicitaban. Estos últimos habitualmente eran bonificaciones tributarias, anticipos sin interés y preferencia para la adquisición de materiales. Respecto de los materiales, es relevante el hecho de que el primer periodo de la construcción de viviendas por parte de RENFE coincide con el periodo autárquico, que vivió gran escasez en determinados materiales de construcción claves, como el acero y el cemento, lo cual provocó no pocas demoras y retrasos en los suministros.

Una vez conseguida esta aprobación inicial se presentaban, ante el mismo organismo y para su aprobación definitiva, los proyectos básicos y de ejecución conforme a las normativas vigentes en el momento, redactados habitualmente por arquitectos de las empresas. A partir de ese momento ya se podía realizar la subasta para la adjudicación de obras y podía darse comienzo a las mismas sin requerirse licencia municipal de obras, aunque sí podía procederse a una revisión por parte de los técnicos municipales, debiendo notificar al INV de todas las situaciones concurrentes (precios contradictorios, retrasos en las obras, modificaciones, retrasos en el suministro de materiales, etc.) con su correspondiente justificación, ya que de manera habitual estas construcciones eran beneficiarias de subvenciones y préstamos. Constatamos la existencia frecuente de reformados de proyecto y revisiones de precios, así como de retrasos motivados por faltas en el suministro de materiales. Las obras terminaban con las recepciones provisional primero y definitiva después firmadas por todos los agentes intervinientes: representante del INV, responsables de RENFE o de la empresa promotora, arquitecto-director de las obras y delegado de la empresa constructora.

El expediente se finalizaba con la liquidación, parcial o total de las obras. Esta liquidación contenía una memoria, unos planos, un presupuesto y un estudio económico. La memoria contenía una relación ordenada cronológicamente de los hechos más relevantes ocurridos tanto en la tramitación del expediente como en la ejecución de las obras. Incluía asimismo una relación ordenada y detallada de todas las certificaciones, cuadro de alquileres y estudio económico de amortización. Aportaba también un precio de ejecución material y un precio final por metro cuadrado construido de vivienda. Los planos generalmente eran el de situación y el de conjunto. El presupuesto incluía detalle de mediciones, cuadro de precios, presupuestos par- ciales y resumen general comparado. Finalmente, el estudio económico contenía detalle de los diferentes presupuestos, como presupuesto de ejecución material, presupuesto de contrata, presupuesto de adjudicación y presupuesto total protegido, donde se incluían los honorarios de proyecto, de dirección facultativa, los derechos obvencionales y el importe de los terrenos. También está presente un cuadro de alquileres anual y mensual, así como el jornal mínimo necesario para hacer frente al mismo. Según el tipo de vivienda, denominadas en orden alfabético habitualmente, se requería un mayor o menor jornal. Por último, incluía un detalle de la financiación. Una vez realizado todo el trámite, las viviendas obtenían la calificación provisional de viviendas protegidas y posteriormente la calificación definitiva.

Además, respecto al suministro de materiales como cemento, hormigón o acero, en el entorno de los años 40 y 50, se debía tramitar con el INV, con petición a la sección de arquitectura, un expediente donde se incluían todas las peticiones de materiales realizadas. Cada petición contenía informe de la Delegación del Gobierno donde se detallaba el destino del material, el total del mismo con detalle anexo de las cubicaciones por unidades de obra firmado por el arquitecto director de obra, la empresa suministradora y el carácter del suministro. Respecto a este último punto, las viviendas protegidas tenían carácter de oficial. A esta petición se respondía desde el INV dándole preferencia o no en el suministro. Durante la autarquía, respecto del uso de los materiales de construcción, establecía el Decreto de 11 de marzo de 1941 (11) las limitaciones en el suministro del acero, en vigor hasta la aprobación de la norma MV-101/1962 sobre “Acciones en la Edificación”. El reglamento de aplicación se basaba en prescribir aquellas soluciones técnicas que contribuyesen al ahorro de hierro, prohibiendo explícitamente su uso en aquellos elementos constructivos que podían ser ejecutados con otros materiales. En el resto de elementos constructivos se instaba al diseño de proyectos que conllevasen mayores economías de hierro.

Todo esto presenta un modo de construir, un modo de hacer ciudad durante más de 20 años que, además, será tomado como "tradición constructiva" cuando la limitación y los condicionantes citados ya habían dejado de existir. En general, la autarquía impuesta limitó el acceso a determinados materiales, provocando su encarecimiento, lo que supuso retrasos en la construcción de las viviendas. En el periodo autárquico, además, el Gobierno era el encargado de distribuir y establecer el precio de los materiales de construcción más relevantes como es el caso del acero y del cemento, en un intento de controlar la inflación, aunque los precios siguieron al alza en los expedientes consultados, lo que obligaba a modificados de proyecto. Así, en nuestros primeros cálculos la diferencia de precios entre el presupuesto inicialmente aprobado, a inicios de la década de 1950, y la liquidación, ya a finales de esa década o comienzos de la siguiente, rondaba un término medio del $30-40 \%$.

\section{NORMATIVA TÉCNICA DE APLICACIÓN}

El análisis de la normativa técnica vigente en el periodo de estudio nos permite entender gran parte de las soluciones constructivas aplicadas. La rigidez normativa, el objetivo del máximo ahorro y la escasez material serán los aspectos claves que condicionarán la materialidad del periodo. 
Las Ordenanzas Técnicas y Normas Constructivas para "viviendas de renta limitada" aprobadas por Orden Ministerial de 12 de julio de 1955 establecían distinción entre dos tipos de viviendas, como se indicaba en la ley de 1954 (ver tabla 1): viviendas de renta limitada del primer grupo y viviendas de renta limitada del segundo grupo. La diferencia fundamental estriba en que para la construcción de las del primer grupo no se solicitaba ayuda económica directa al Estado mientras para las segundas sí. Este segundo grupo se subdividía a su vez en tres categorías en función de su superficie y presupuesto por metro cuadrado. Para el caso en estudio, todas las viviendas ferroviarias corresponden al grupo segundo y generalmente a la segunda categoría dentro del mismo.

El antecedente a la normativa citada era la orden de 24 de febrero de 1944 (12), a propuesta de la Comisión de Sanidad local consistente en un compendio de 14 preceptos, muchos de los cuales se recogieron en la Orden de 1955. Ambas normativas engloban la totalidad de los proyectos y expedientes consultados hasta el momento y cuya construcción abarca el periodo comprendido entre 1950-1964.

Así como las prescripciones para las viviendas del primer grupo se limitan a que la edificación debe cumplir con las ordenanzas municipales existentes, para las del segundo grupo se establecen: contenidos mínimos de proyecto, detalle de los proyectos de urbanización en consonancia con el planeamiento existente, aptitud de los terrenos y su valoración. Respecto a la composición y programa de las viviendas se exigía un mínimo de tres dormitorios, cocina-comedor y retrete con entrada independiente. Ello conllevó una excesiva compartimentación a pesar de la limitada superficie de la vivienda, con una media de $65 \mathrm{~m}^{2}$ en los casos analizados, con lo que las dimensiones de las estancias eran mínimas sin existir, en el caso analizado, planteamientos experimentales como los utilizados en Europa que permitieran una composición de células más flexible y adaptable a las diferentes formas de habitar. Es decir, eran soluciones de "higienismo planimetrico" (13), resultado de la estricta aplicación de la normativa vigente.

Como cuestión más vanguardista, se permitía un porcentaje de "viviendas crecederas", es decir, aquellas que contasen con un único dormitorio, en el que necesariamente debía caber cama de matrimonio y cuna, siempre y cuando el proyecto se acompañase del desarrollo total, objetivo final, de estas viviendas. También la ordenanza limitaba la libertad proyectual respecto a diseños singulares basándose en lo estrictamente funcional como forma de reducir costes.

También estas normativas establecían mínimos y máximos de altura libre de planta, tanto en el medio rural como en el urbano, siendo el origen de los 2,50 m de altura libre de planta de las viviendas actuales; modelo que será adoptado en las ciudades lo que necesariamente conllevó una mayor densificación de la ciudad.

Una de las cuestiones básicas para la correcta ventilación de las viviendas es el establecimiento del lado mínimo de patio interior a $3 \mathrm{~m}$, así como su superficie a $10 \mathrm{~m}^{2}$. Los patinillos y chimeneas de ventilación quedan descartados, excepto muy justificadas excepciones. También, para el buen soleamiento de las viviendas, se limita la altura de los edificios en función de la anchura de calle, se establecen como orientaciones predominantes la sur y la este, así como la superficie mínima de ventilación por estancia al $10 \%$ de su superficie. Ello condicionará la composición de un buen número de fachadas con ventanas excesivamente pequeñas.

La misma normativa establece las dimensiones mínimas de cada estancia y en concreto, las dimensiones del "cuarto capaz para hacer la vida familiar", la cocina o comedor. Respecto a los aseos, se establece un chapado mínimo o un revestimiento impermeable hasta 1,40 m del suelo. Debían contar como mínimo con retrete con cierre hidráulico, lavabo y ducha. Igualmente es preceptiva la instalación de agua caliente. Como norma de economía y normalización se impone el uso de media bañera o ducha en las viviendas de $2^{\mathrm{a}}$ y $3^{\mathrm{a}}$ categoría. En las escaleras, se limitan anchuras mínimas de tramo, de meseta, dimensiones mínimas de huella y contrahuella y condiciones de las barandillas.

Respecto de normas urbanísticas, se establece de forma obligatoria que los bloques que se implanten en núcleos urbanos de nueva creación deban ser de dos crujías. Ello va a limitar el tamaño de vivienda a los permitidos para esta categoría, garantizar la ausencia de patios interiores y permitir la ventilación natural de todas las estancias, limitando además las soluciones estructurales $(14)^{2}$.

Acerca de la distancia entre bloques paralelos, disposición muy común para garantizar las mismas condiciones de soleamiento a las viviendas, ésta no será menor que su altura.

Con respecto de los materiales permitidos, para la construcción de muros se limita el uso del tapial y el adobe a aquellas zonas donde su uso es tradicional; acerca de la mampostería se condiciona su uso mientras que al ladrillo se le considera adecuado en cualquier situación. También se autorizan los muros de carga de hormigón armado o sin armar y los entramados se limitan a aquellos que empleen cuajados y revestimientos aceptados por el INV.

Para los forjados se permiten los de madera, escuadra o en rollo, los planos armados y los formados por bóvedas tabicadas. Tanto estas últimas como los forjados cerámicos, denominados también autárquicos, fueron de uso generalizado debido a las condiciones del momento. Se limita el uso de acero, se establece un canto de forjado máximo de $18 \mathrm{~cm}$, y se limitan las luces y los pesos por metro cuadrado. Para las cubiertas se prohíben las estructuras en par e hilera, excepto casos excepcionales, y los materiales de acabado se limitan a tejas (plana y curva), pizarra, fibrocemento y cartón impregnado.

Respecto al aislamiento térmico, se divide España en dos zonas climáticas: la zona 1 , con temperaturas extremas entre $-5^{\circ}$ y $30^{\circ}$ centígrados; y la zona 2 , el resto. Para la segunda zona se establece como forma de conseguir el aislamiento térmico adecuado el espesor de los muros y la disposición en cubierta de algún material aislante. Para la primera zona no

\footnotetext{
2 Las cuestiones tipológicas de diseño de bloque y célula quedan fuera del presente trabajo. A este respecto resulta fundamental la aportación de Paricio Ansuátegui.
} 
prescribe explícitamente el uso de aislantes y en el grupo de proyectos estudiados, no aparecen éstos ni en las memorias constructivas ni en los correspondientes planos. Por último, como normas de economía y normalización se imponían límites a la cantidad de materiales de construcción empleados en función del tipo de vivienda que se tratase.

Finalmente, y tras algunas mejoras y revisiones, las "Normas Técnicas de Diseño y Calidad de la Vivienda Social", elaboradas por la Dirección General de Arquitectura y Tecnología de la Edificación, fueron aprobadas en la Orden de 24 de noviembre de 1976 y posteriormente revisadas por la Orden de 17 de mayo de 1977 (15) derogando cuantas normas de igual o inferior rango relativas al diseño de viviendas sociales.

En el análisis de los proyectos se observa el cumplimiento de las ordenanzas de aplicación citadas, así como repetición de gran parte de las soluciones constructivas que seguidamente se detallan. En general se estandarizaban los mínimos exigibles, así como un gran número soluciones constructivas y se obvian todas las soluciones experimentales del periodo anterior (16). Ello conlleva también una imagen estandarizada de ciudad que perdura y permite distinguir la época de construcción entre unos bloques y otros.

\section{ANÁLISIS DE PROYECTOS Y SOLUCIONES CONSTRUCTIVAS APLICADAS EN LOS PROYECTOS DE VIVIENDA FERROVIARIA}

Hasta el momento, la mayor parte de los proyectos localizados y estudiados corresponden a 42 promociones de viviendas repartidas por toda España, perteneciendo 34 a los construidas por RENFE y el resto son de cooperativas de empleados ferroviarios. Respecto de los proyectos de RENFE, se observa una repetición prácticamente exacta de aquellos proyectos redactados por el mismo facultativo a pesar de ubicaciones dispares o de condiciones climatológicas completamente diferentes.

El grueso de los proyectos analizados, custodiados en el Archivo del Ministerio de Fomento, se engloba en el periodo comprendido entre 1945 (Zaragoza El Portillo) y 1960 (Barcelona Diagonal III) y, como características constructivas generalizables aparece el empleo de la mal denominada construcción tradicional (17), la consecuente ausencia de prefabricación prácticamente reducida a la carpintería de taller, el predominio de la construcción basada en el ladrillo, la restricción en el uso del acero, propia del periodo autárquico al que pertenecen estos proyectos, y la repetición de soluciones constructivas. Destaca asimismo la casi total ausencia de disposición de aislamientos térmicos, y en ningún caso se trata el tema del aislamiento acústico, consecuencia de la escasa y ambigua normativa existente al respecto.

Transcurrida una década del periodo de estudio, resultan destacables los cuadros comparativos que el ingeniero Presa Santos (1972) realiza entre varios países europeos a un lado y otro del telón de acero respecto del nivel de prefabricación en la construcción de viviendas alcanzado en base a datos de la ONU. La diferencia es abismal: en ningún país de Europa occidental estaba implantada la prefabricación en la construcción de viviendas excepto en ejemplos puntuales mientras que, en Europa oriental o la URSS la prefabricación era habitual. Paradójicamente, los sistemas cons- tructivos estaban mucho más desarrollados en Europa occidental (18).

Respecto a los contenidos mínimos de proyecto y a las prescripciones técnicas contenidas, aunque no se conservan íntegros la mayoría de los proyectos analizados, sí se puede reconstruir el contenido tipo de proyecto por análisis de los proyectos de vivienda coetáneos. Así, estos proyectos contaban con Memoria, que incluía tanto las cuestiones descriptivas y funcionales como las cuestiones técnicas; Pliego de condiciones (facultativas o técnicas particulares y generales y económicas); Presupuesto (incluye mediciones, cuadro de precios, presupuestos y estudio económico); y Planos. A medida que avanzamos en el tiempo, se observa una mayor descripción y precisión de los aspectos técnicos que, en los primeros proyectos se limitan básicamente a escuetos apuntes donde se repiten materialidad y soluciones constructivas mientras que en los últimos precisan con mayor detalle las diferentes partidas.

Acerca de los sistemas estructurales empleados, la prescripción normativa antes citada para núcleos de nueva creación (v. gr. Villaverde Bajo, figura 1), de la solución estructural de bloque de dos crujías, entre 8 y $9 \mathrm{~m}$ de luz total y aproximadamente 4,5 m de luz entre apoyos, se generalizó ya que determinaba un tipo de célula idóneo para la vivienda social tanto por superficie como por cuestiones de higiene y de economía, debido a que todas las piezas contaban con ventilación directa con el consiguiente ahorro de construcción de patios interiores. La materialización de dicha solución se efectuaba mediante muros de carga de ladrillo en fachadas y línea estructural paralela interior normalmente también constituida a base de muro de fábrica y que servía además para apoyo de la cumbrera y anclaje de las tirantillas de cubierta. Excepcionalmente, esta línea estructural intermedia, se ejecutaba mediante soportes de hormigón armado, como hemos visto en 6 de las 42 promociones estudiadas, ya que tanto la restricción impuesta en el uso de acero como los problemas en el suministro de materiales desaconsejaban esta opción. Los muros de arriostramiento se disponían en las medianeras, sobre todo cuando se trataba de viviendas agrupadas, o en el cierre de las cajas de escalera.

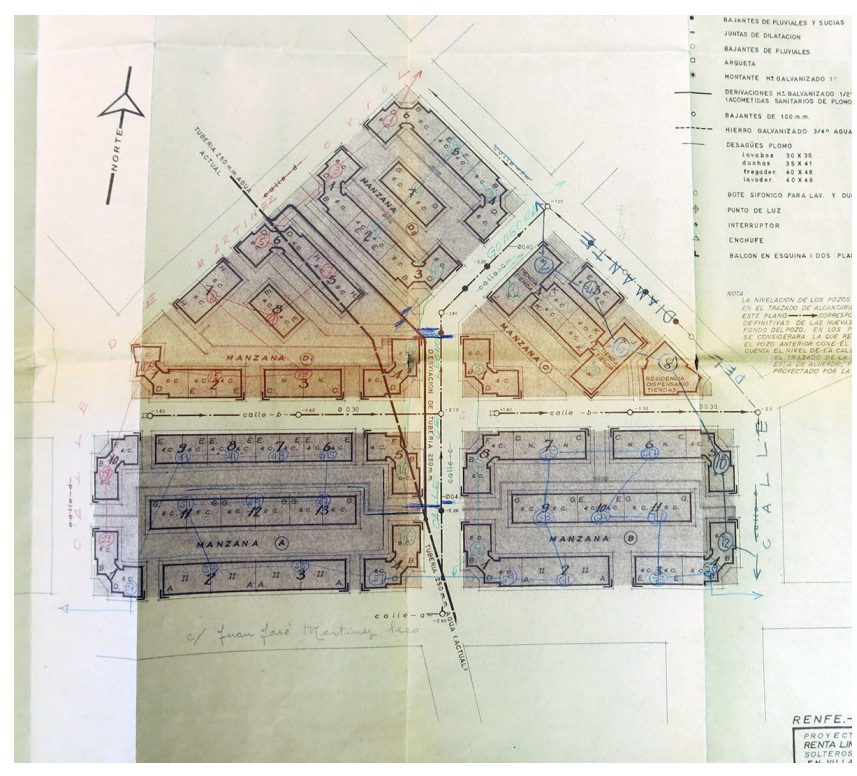

Figura 1. Planta general de grupo viviendas RENFE en Villaverde Bajo (Madrid). Archivo del Ministerio de Fomento (AMF), proyecto M-7394-RL (1958). 
Acerca de los espesores, en la mayor parte de los casos estudiados de bloque en altura se emplea el tradicional decrecimiento en altura para aligeramiento de la fábrica a pesar del menoscabo de cuestiones de aislamiento que no se tenían en cuenta (figura 2). Así, encontramos muros de asta y media en las plantas bajas ( $43 \mathrm{~cm}$, sin contar revestimientos) que se reducen a un asta ( $28 \mathrm{~cm}$, sin revestimientos) en las plantas superiores. No es posible detallar los aparejos empleados porque otra característica común de la forma de redacción de los proyectos es que el nivel de detalle constructivo era muy básico y escueto y porque la mayoría de las fábricas eran revestidas. No obstante, en las promociones visitadas hasta el momento donde se emplea ladrillo visto se ejecutan citaras de asta con ladrillos a tizón. El rejuntado más común detallado en los proyectos consultados era mortero de cemento de 200-250 kg por $\mathrm{m}^{3}$. Las fábricas se prescribían "a buena traba” con ejecución de llaves en los encuentros y también se prescribía una anchura de tendeles no superior a los $12 \mathrm{~mm}$.

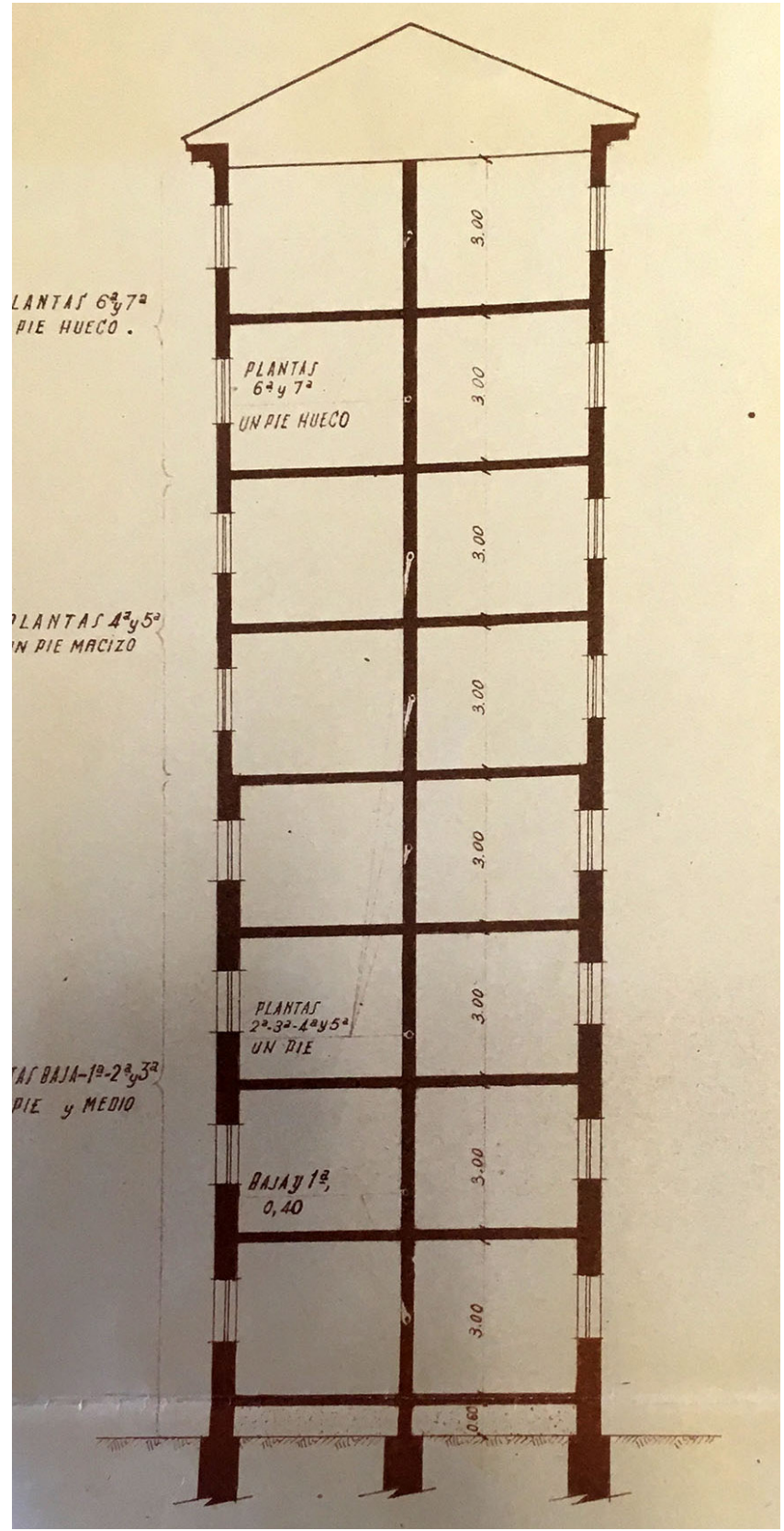

Figura 2. Sección tipo de grupo de viviendas RENFE en el Paseo de las Delicias (Madrid). AMF, proyecto M-1611-VP (1946).
Es de reseñar que únicamente en el proyecto de la cooperativa de Ciudad Real, a finales de los años 50, el proyecto detalla lámina aislante entre la cimentación y el arranque de los muros de fábrica.

Resultan singulares las propuestas para 48 viviendas en San Cayetano, en Córdoba, o las 97 viviendas de Las Matas, en Madrid (figura 3), que combinan muro de mampostería concertada para las plantas bajas con disposición de perpiaños y el resto fábrica de ladrillo revestida $\mathrm{y}$, en ninguno de los casos estudiados, se emplea estructura reticular de hormigón armado o perfiles de acero, por las cuestiones antes citadas, a pesar de lo generalizado de estas soluciones en Europa o Estados Unidos y de las experiencias españolas del periodo anterior.

Para los conjuntos de viviendas unifamiliares en hilera se proyectaba también la solución en muros perpendiculares a la fachada y en este caso, los de la fachada hacían la función de arriostramiento.

Para la cimentación, dado el sistema estructural descrito, la solución más repetida era la de zanjas corridas, normalmente de hormigón en masa y en menor medida a base de mampuestos (v. gr., El Escorial), y, en los casos de crujía intermedia a base de pilares, se combinaban con zapatas aisladas en la línea estructural correspondiente que no se ataban (v. gr., Málaga o Zaragoza), (figuras 4 y 5). Sólo en algunos casos (v. gr., Algodor) se recurre a cimentación a base de pozos (figura 6). Para el caso de las viviendas próximas a la estación

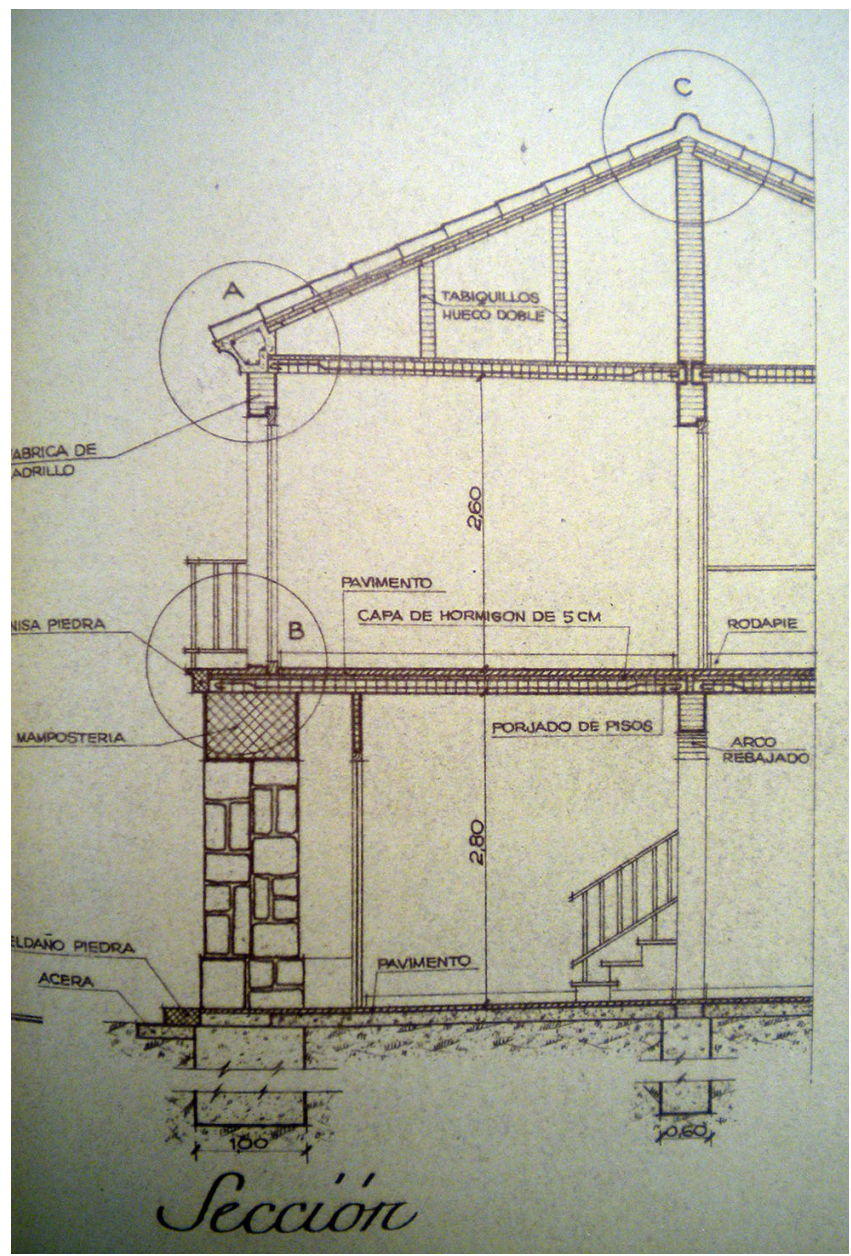

Figura 3. Sección constructiva de grupo viviendas RENFE en Las Matas (Madrid). AMF, proyecto M-5476-VP (1957). 


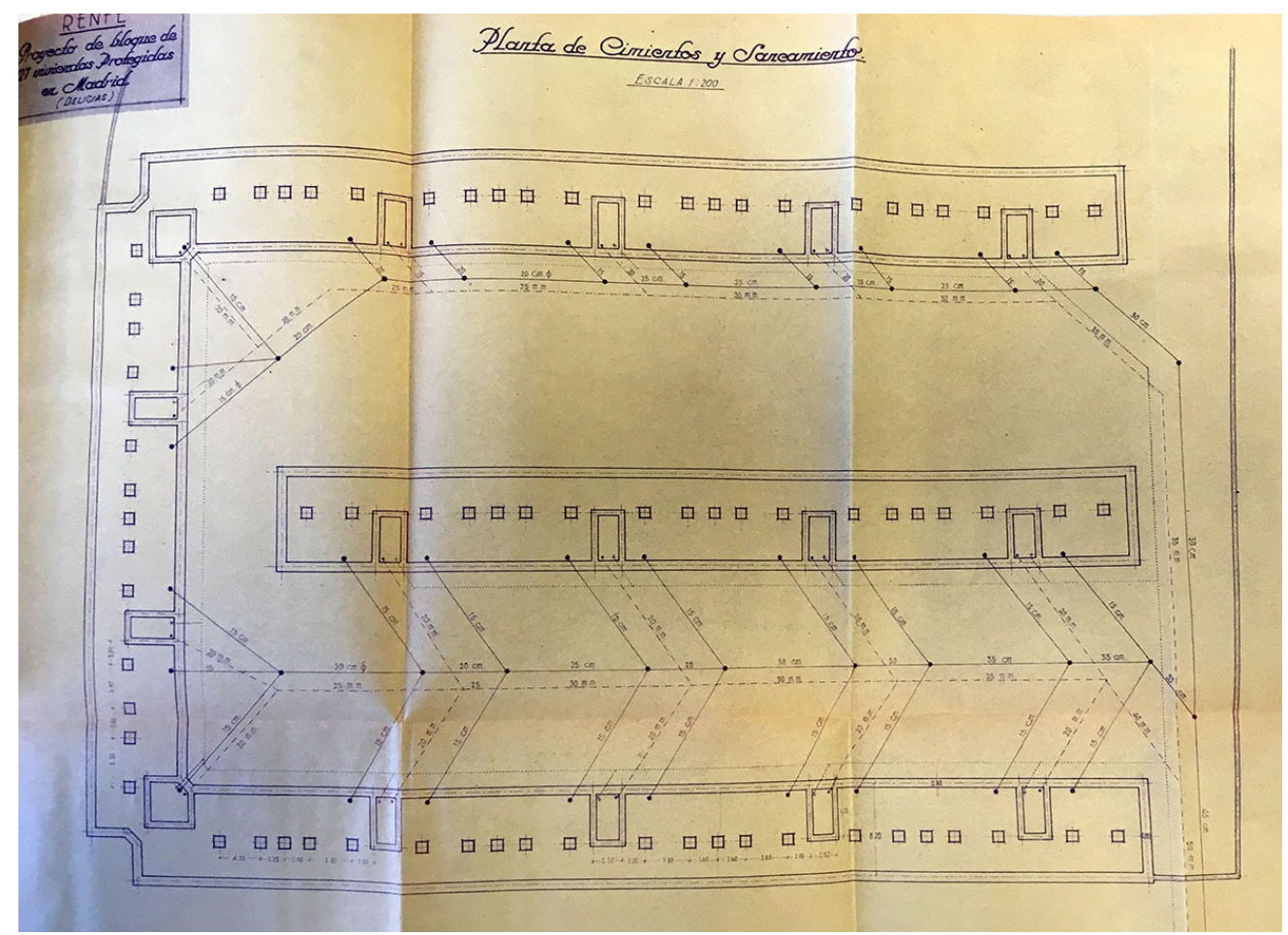

Figura 4. Planta de cimentación de grupo de viviendas RENFE en el Paseo de las Delicias (Madrid). AMF, proyecto M-1611-VP (1946).

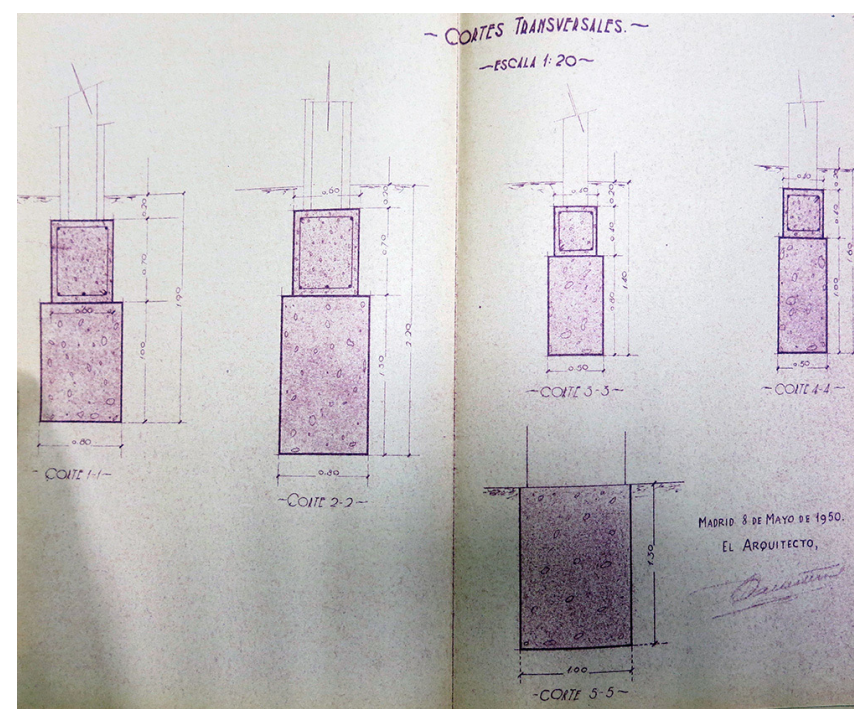

Figura 5. Sección de cimentaciones tipo en el grupo de viviendas RENFE en Algeciras (Cádiz). AMF, proyecto CA-1882-VP (1947).

de Sevilla-Plaza de Armas, el proyecto determina la cimentación a base de pilotes, aunque no figuran detalles de los mismos. Sobre la cimentación, y hasta la rasante del terreno, se rellenaba con hormigón de carbonilla en espesores comprendidos entre 20-30 cm. El hormigón empleado para las zanjas o pozos era hormigón en masa de $200 \mathrm{~kg}$ de cemento por $\mathrm{m}^{3}$.

En ninguno de los casos estudiados se proyecta la ejecución de sótano y sólo en cinco casos se proyecta la ejecución de forjado sanitario en lugar de solera. Debemos tener presente que el criterio de ahorro económico era uno de los principios básicos impuesto ya desde la propia normativa. Resulta singular la descripción de las 64 viviendas proyectadas en Ciudad Real por RENFE (pero que no se llegaron a construir), donde la separación con el terreno se ejecuta mediante "cámara catalana

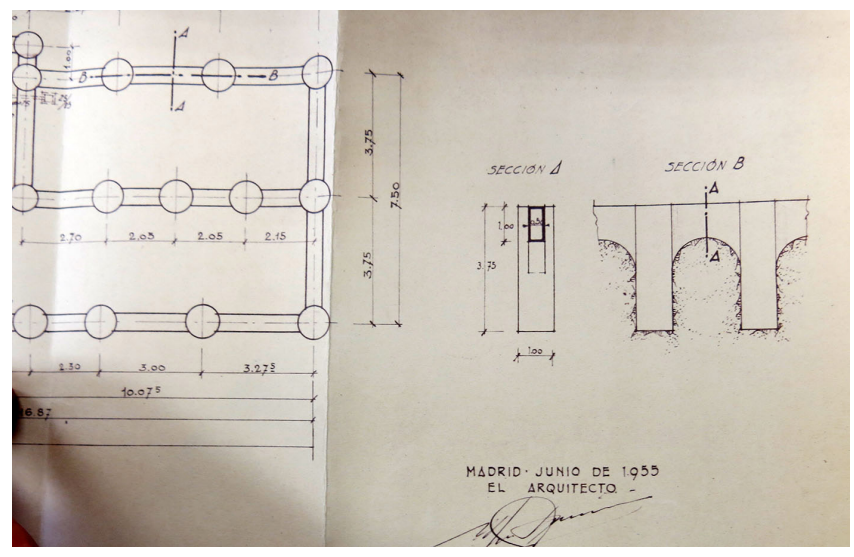

Figura 6. Planta y sección cimentación por pozos en el grupo de viviendas RENFE en Algodor (Madrid). AMF, expediente M-5933-VP (1956).

sobre la solera”. Esta solución era la misma que se aplicaba en las cubiertas planas, aunque en este caso en lugar de sobre forjado la cámara se ejecutaba sobre solera sobre capa de carbonilla. En las 65 viviendas de RENFE de la manzana N de Cuatro Caminos se emplea la misma solución y se detalla que la misma se ejecuta mediante forjado de ladrillo hueco doble armado dejando una cámara de $40 \mathrm{~cm}$ con la solera.

Respecto a vigas, dinteles o cargaderos, realizados en hormigón armado, se trata de elementos diseñados en cuelgue para reducir así la cantidad de acero empleada. Se describe un tipo de hormigón entre 250-350 kg de cemento por $\mathrm{m}^{3}$. Los hormigones de 300-350 kg de cemento se denominaban "hormigón normal". El hormigón armado se empleaba para cargaderos de crujía de luz máxima media de 4,50 m o bien para cargaderos de apoyo de escaleras de luz media de $2 \mathrm{~m}$. Para dinteles de vanos no se proyectaba la ejecución de cargaderos, del mismo tipo de hormigón, a no ser que la luz fuese mayor a 1,20 m. En 
el caso de las 64 viviendas de renta limitada de Ciudad Real no se disponen los mismos en luces menores a 1,40 m. El ahorro que ello conlleva hace que, en este tipo de viviendas proyectadas en estos años en su mayoría a base de muros de carga como se detalla anteriormente, las dimensiones más habituales de los huecos de fachada sean de entre 1,00-1,20 m. En ningún caso de los estudiados se emplean soluciones estructurales a base de perfiles normalizados de acero que, sin embargo, habían sido empleados hasta 1936 (19).

En cuanto a las armaduras, los pliegos prescribían el doblado en frio, el atado mediante alambre o taco de hormigón y los solapes con longitudes superiores a $30 \mathrm{~cm}$, soldando los alambres de unión entre barras. Los recubrimientos eran de un diámetro admitiendo errores de medio diámetro. Hemos de apuntar que estos mínimos recubrimientos, piénsese en el empleo de barras del 8-10, son inadmisibles en la actualidad siendo una de las principales causas de patologías comunes en los elementos de hormigón armado en este tipo de viviendas. Antes del hormigonado, se prescribía la presencia de, además del director de la obra, del técnico de la contrata que tenía que asegurarse de la correcta colocación de las armaduras.

Acerca de los forjados, unidireccionales lógicamente, predominan los forjados autárquicos basados en el empleo de materiales cerámicos como elementos aligerantes y nervios in situ. La losa superior de forjado se ejecutaba de $405 \mathrm{~cm}$ de espesor. En los casos en estudio se observan cantos de forjado que oscilan entre los 13 y los $20 \mathrm{~cm}$. Aunque la solución más empleada es la de canto de $15 \mathrm{~cm}$. Se componen de ladrillos huecos dispuestos cada $25 \mathrm{~cm}$ (longitud de la soga), dejando un espacio de 5 cm para los nervios y el hormigonado conjunto junto a la losa superior de forjado (figuras 7 y 8). La dosificación más repetida es la de 1:2:3, empleando $340 \mathrm{~kg}$ de cemento por $\mathrm{m}^{3}$.

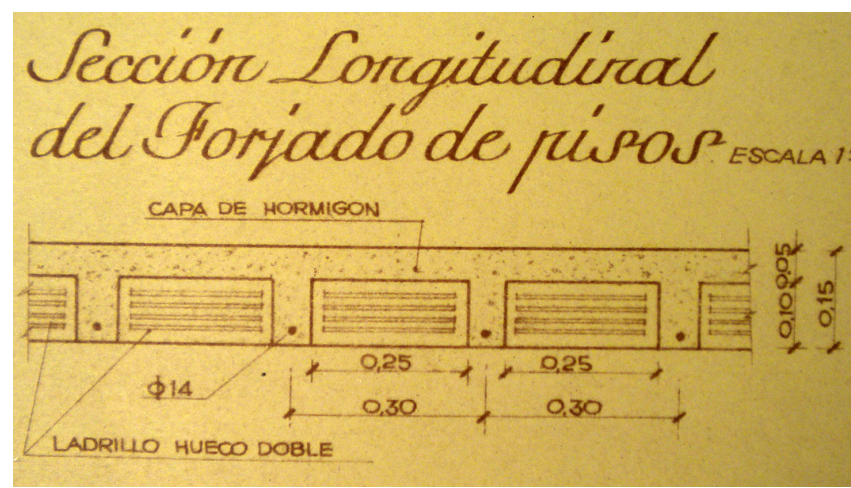

Figura 7. Sección de forjado autárquico del grupo de viviendas RENFE en Las Matas (Madrid). AMF, proyecto M-5476-VP (1957).

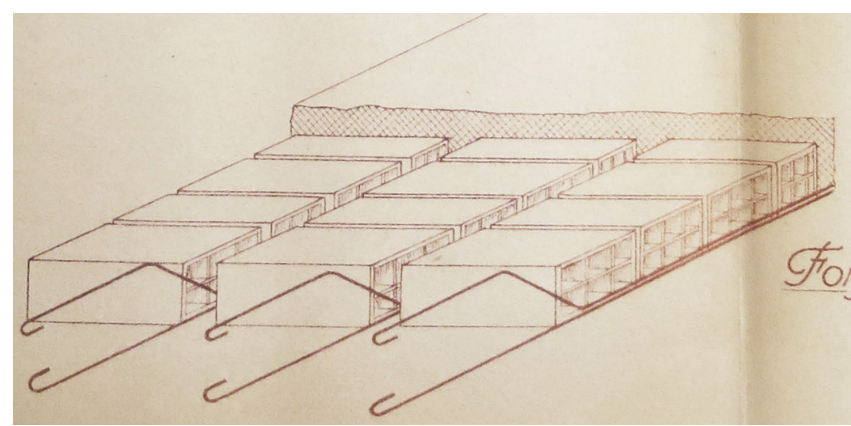

Figura 8. Perspectiva de forjado autárquico del grupo de viviendas RENFE en el Paseo de la Alameda (Valencia). AMF, proyecto V-1981-VP (1948).
Explícitamente se desdeña en los proyectos anteriores a 1957 cualquier tipo de forjado prefabricado por considerar que "se arman escasa y únicamente para su rigidez antes de colocarlos en su situación definitiva completándose después el armado con los pequeños nervios que los unen. Esto, que teóricamente es perfecto, tiene los riesgos de las imperfecciones de prefabricación y las averías por deformaciones al elevar las viguetas a las plantas" (20).

Por ese motivo, aunque en el caso en estudio sólo hemos encontrado el empleo de bóvedas cerámicas para la construcción de escaleras (figura 9), se generalizó bastante su uso para los forjados de piso siendo las viviendas en el barrio de Usera de Luis Moya un interesante ejemplo de ello (21, 22). En nuestro caso, las mismas se aplican en escaleras de dos y tres tramos y se constituyen generalmente de dos roscas de rasilla dispuestas a tabla, la primera, denominada "sencillo", tomada con yeso negro, y la segunda, "doblado" con cemento. En algunos casos como el del detalle aportado, se ejecutan tres roscas tomando con yeso la primera y las siguientes con cemento.

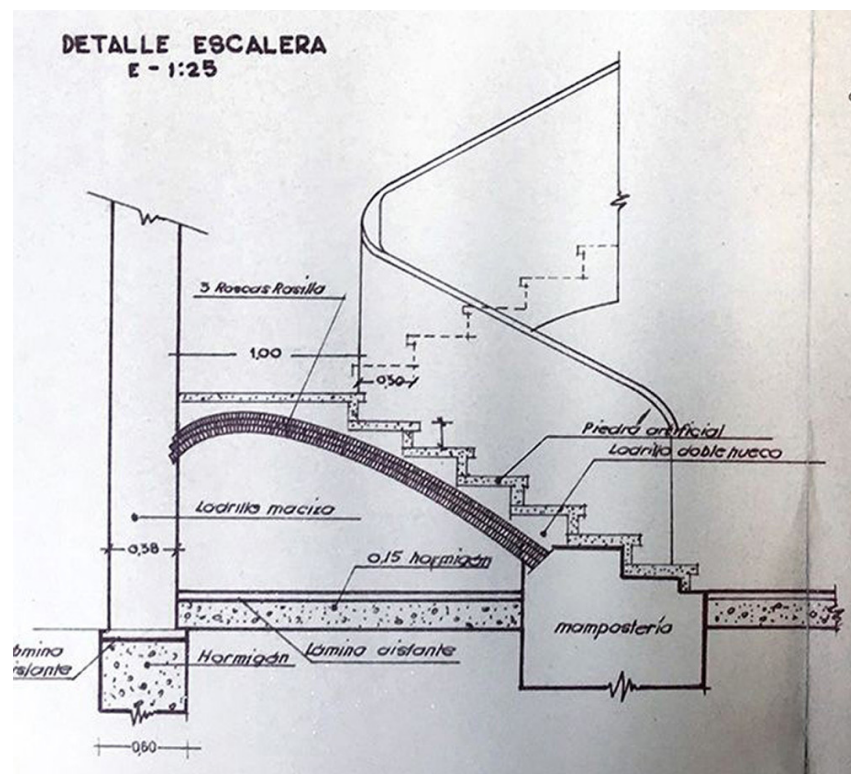

Figura 9. Bóveda de escalera típica. Viviendas de la cooperativa Nuestra Sra. De Alarcos y San Rafael Arcángel, primera fase, de Ciudad Real. AMF, proyecto CR-5031-RL (1958).

Los 3 o 4 primeros peldaños se ejecutaban sobre macizo de ladrillo, los arranques de los tiros de cada tramo sobre los anteriores ya ejecutados se realizaban sobre la rosca de cemento aparejando los tiros para que quedaran bien trabados, para ello era habitual la disposición de las rasillas de la segunda o siguientes roscas montadas a $45^{\circ}$ con respecto a la primera. Los rincones de arranque en los riñones de la bóveda se macizaban con mortero de cemento para garantizar la estabilidad. Otra característica de esta técnica constructiva es que las hojas tenían una cierta curvatura hacia la roza ejecutada en el muro. Es decir, mirando por el intradós, la arista exterior de la bóveda estaba unos centímetros elevada respecto de la tangente al muro. Posteriormente, los peldaños se ejecutaban mediante ladrillo hueco revistiendo como acabado tabicas y huellas mediante piedra artificial habitualmente.

En los proyectos de cooperativas analizados, que corresponden a las fechas más tardías, en el arranque de la déca- 
da de 1960, y ya superado el periodo autárquico, se observa el cambio a tipos de forjados unidireccionales compuestos mediante viguetas prefabricadas tipo I, concretamente viguetas Castilla, empresa fundada en ese momento por el ingeniero de caminos José Cámara Rica, es la prescrita en la totalidad de proyectos analizados hasta el momento. Por ejemplo, el detalle del forjado empleado en la construcción de la primera fase de 104 viviendas de la cooperativa de Ciudad Real "Nuestra Señora de Alarcos y San Rafael Arcángel" presenta un canto de forjado de $18 \mathrm{~cm}$, sin detallar losa superior de forjado, y donde el entrevigado se ejecuta mediante doble rosca de rasilla. El intradós del forjado se conforma plano mediante la ejecución de revoltón de ladrillo sencillo y el extradós se nivela mediante el relleno de hormigón en los huecos que quedan entre la rasilla y la vigueta (Figura 10).

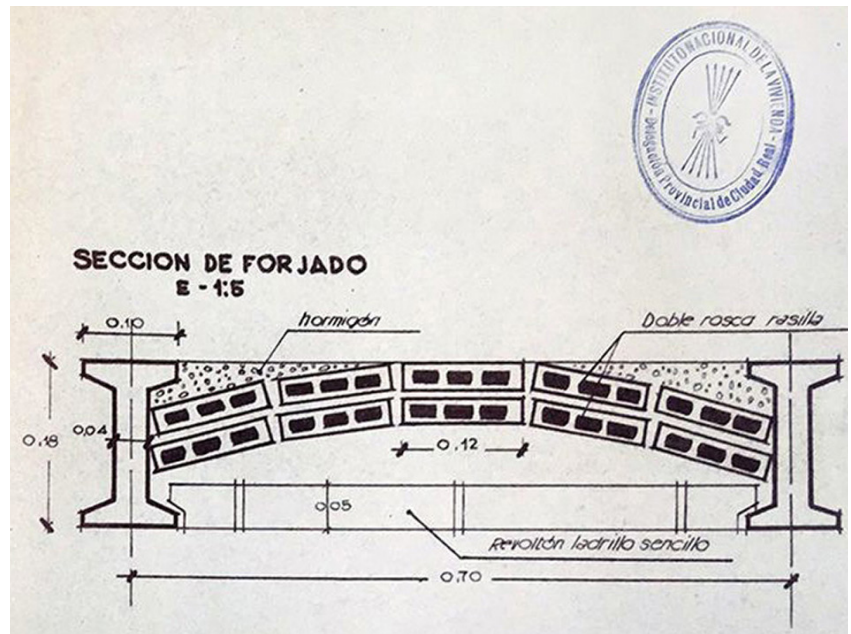

Figura 10. Sección forjado viguetas "Castilla”. Viviendas de la cooperativa Nuestra Sra. De Alarcos y San Rafael Arcángel, primera fase, de Ciudad Real. AMF, proyecto CR-5031-RL (1958).

Acerca de los cerramientos, se obvia toda la evolución técnica desarrollada en las décadas precedentes (23). Así, los proyectos analizados prescriben cerramientos de una hoja, constituidos por los muros de carga, sin observarse ningún tipo de cámara o de doblado interior que, si bien no es propia de este sistema estructural, lo cierto es que la reducción de espesor, el empleo de ladrillo y la presencia de puentes térmicos no garantizan el adecuado aislamiento térmico3. Tampoco se grafía en planta o sección ninguna composición multicapa ni para fachadas, ni para medianeras o muros hastiales. Hasta el momento, únicamente el proyecto de 300 viviendas de la citada cooperativa de Ciudad Real, que era la tercera fase y más tardía, prescribe el doblado de muro de carga a base de ladrillo caravista con hoja interior a base de ladrillo hueco sencillo dejando cámara de aire intermedia que ya es de reducidas dimensiones. Es decir, ya se tiene en cuenta la ineficacia respecto del aislamiento térmico, de cámaras de espesores mayores a $8 \mathrm{~cm}$.

La tabiquería interior se ejecuta a base de ladrillo hueco sencillo, de $4,5 \mathrm{~cm}$ de espesor medio, guarnecido y maestrado con yeso negro y posteriormente blanqueado a la llana.
Acerca de las cubiertas, en 30 de las 42 promociones estudiadas hasta el momento se emplea cubierta inclinada a dos o cuatro aguas. El resto se ejecuta mediante cubierta plana transitable a la catalana o plana no transitable.

Una solución bastante generalizada para la ejecución de las cubiertas inclinadas se basaba en el empleo de tirantes de acero redondo y tirantillas de madera anclados a los muros exteriores y al muro central mediante durmientes. El intradós se cubría con cañizo y yeso. Los pares e hilera se ejecutaban mediante escuadrías de madera de dimensiones estimadas de $18 \times 8 \mathrm{~cm}$ sobre tablero de ripia. El acabado más común era a base de teja árabe recibida con mortero de $200 \mathrm{~kg}$ de cemento. Esta solución fue generalizada en los casos estudiados por el ahorro en el uso del hierro prescrito y porque la normativa alentaba al diseño de soluciones constructivas con el mínimo uso de este material (figuras 11 y 12). En periodos posteriores, otras soluciones adoptadas fueron la de las viviendas de la manzana $\mathrm{N}$ de Cuatro Caminos (Madrid) donde la cumbrera y las vigas de apoyo se diseñan en hormigón arma-

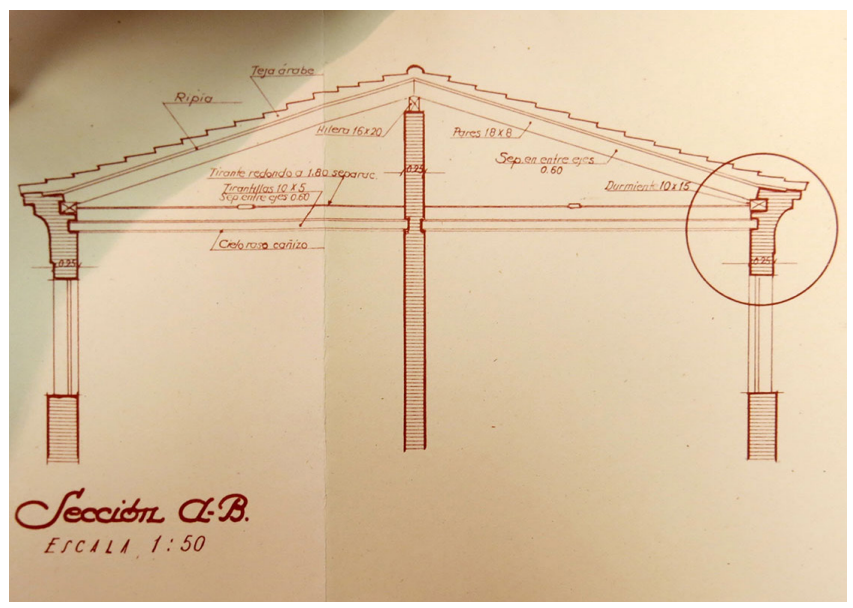

Figura 11. Sección de cubierta de grupo de viviendas de RENFE en el Paseo de las Delicias (Madrid). AMF, proyecto M-1611-VP (1946).

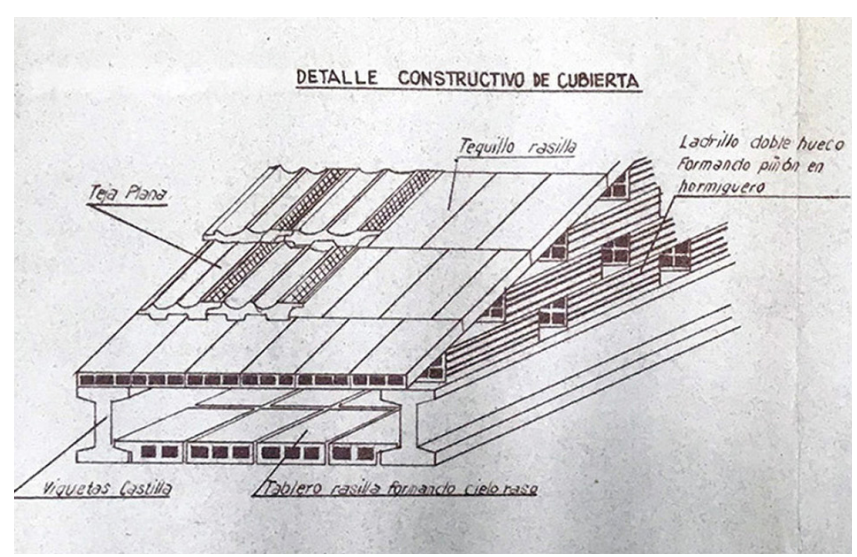

Figura 12. Detalle de cubierta. Viviendas de la cooperativa Nuestra Sra. De Alarcos y San Rafael Arcángel, primera fase, de Ciudad Real. $\mathrm{AMF}$, proyecto CR-5031-RL (1958).

\footnotetext{
3 Se realiza una simulación de cálculo de eficiencia energética como elementos aislados de las fábricas presentes en las viviendas estudiadas con la aplicación CERMA v.4.2 obteniendo como resultando que sólo las fábricas de ladrillo perforado de un determinado tipo, de 2 pies de espesor, alcanzan el valor límite máximo permitido ( $\left.\mathrm{U}=0.94 \mathrm{~W} / \mathrm{m}_{2}^{\circ} \mathrm{C}\right)$ en las 4 zonas climáticas más benignas (A1 a $\left.\mathrm{A} 4\right)$ de las 16 establecidas por el Código Técnico.
} 
do en forma de $\mathrm{T}$ para refuerzo de los apoyos del forjado autárquico (figura 13).

Las cubiertas planas (figura 14), se ejecutaban "a la catalana" disponiendo tabiquillos a base de ladrillo sencillo cada 60 $\mathrm{cm}$, aproximadamente. El tablero se ejecutaba a base de rasilla y la pendiente media era del $4 \%$. Se prestaba especial atención a las juntas de dilatación y a la junta perimetral. El acabado era a base de rasilla. La ventilación de la cámara se solucionaba mediante la disposición de tubos de pequeño diámetro o de disposición de piezas huecas con los orificios transversales al plano de fachada.

Los revestimientos exteriores más empleados eran los revocos y enfoscados a base de morteros de cal o cemento. Se admitía el uso de morteros con argamasa prescribiéndose el empleo de cales grasas, morteros de cal hidráulica y morteros de cemento tipo portland en diferentes dosificaciones. En todos los casos, la cantidad de agua la prescribía el arquitecto.

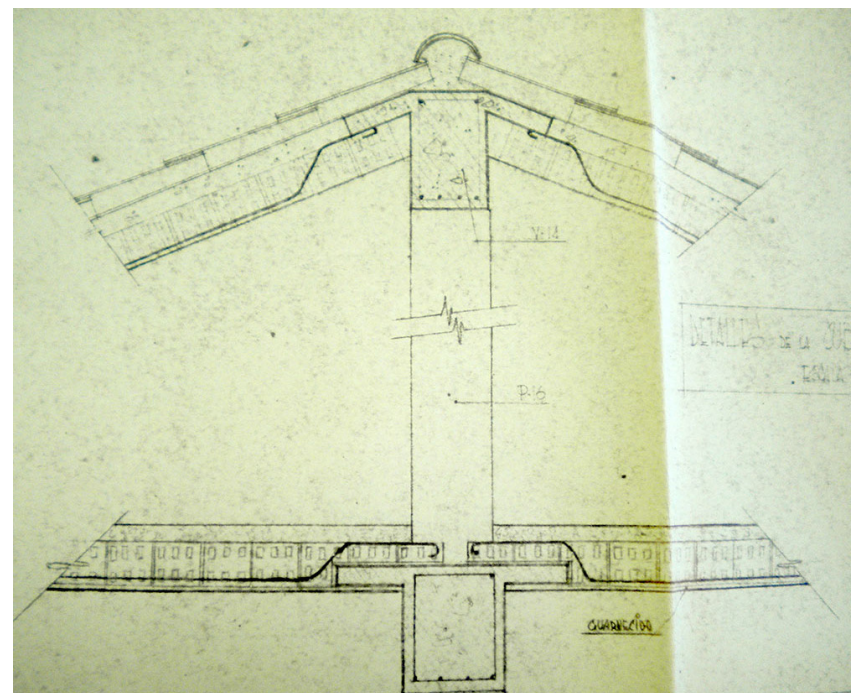

Figura 13. Detalle de cubierta de grupo de viviendas RENFE de Cuatro Caminos-manzana N (Madrid). AMF, proyecto M-5260-RL (1953).

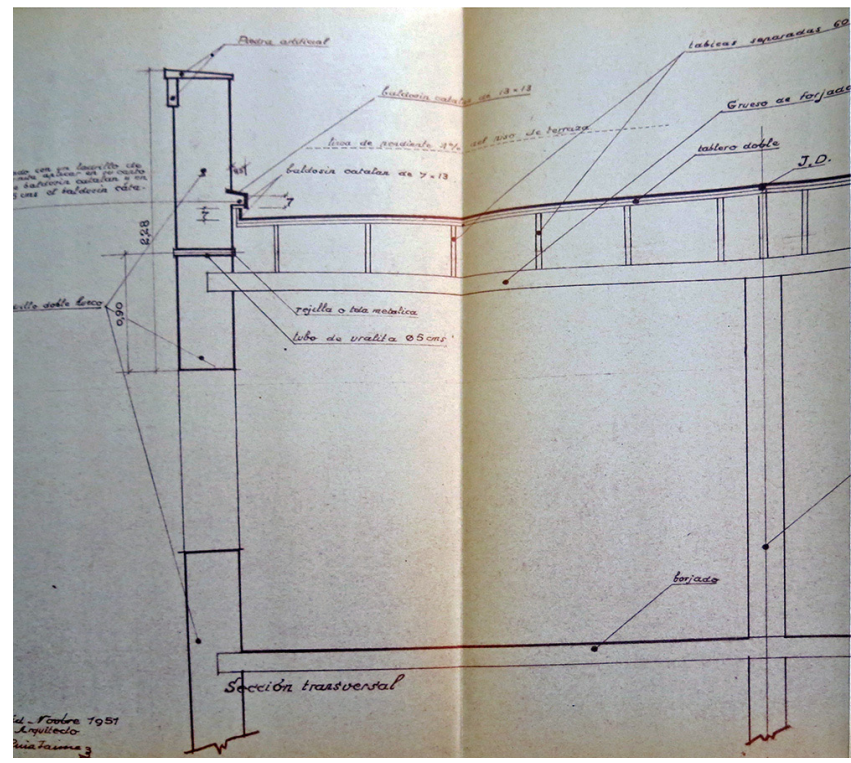

Figura 14. Detalle de cubierta de grupo de viviendas RENFE del Paseo de la Alameda (Valencia). AMF, proyecto V-1981-VP (1948).
Los revestimientos interiores eran guarnecidos y enlucidos de yeso y pintura, excepto en cuartos húmedos donde se ejecutaba alicatado cerámico, bien hasta media altura $(1,4 \mathrm{~m})$, bien hasta el techo, mediante piezas esmaltadas blancas de dimensiones 15x15 o $20 \times 20 \mathrm{~cm}$. Los solados eran a base de baldosín hidráulico, y las carpinterías interiores y exteriores de madera de pino del país con acristalamientos sencillos de $4 \mathrm{~mm}$ de espesor (figura 15). Es en estos elementos donde se encuentra el mayor grado de industrialización dentro del caso en estudio. Respecto de piezas especiales, únicamente la celosía empleada en las viviendas de Villaverde Bajo (figura 16) supone una excepción dentro de la uniformidad constructiva encontrada.

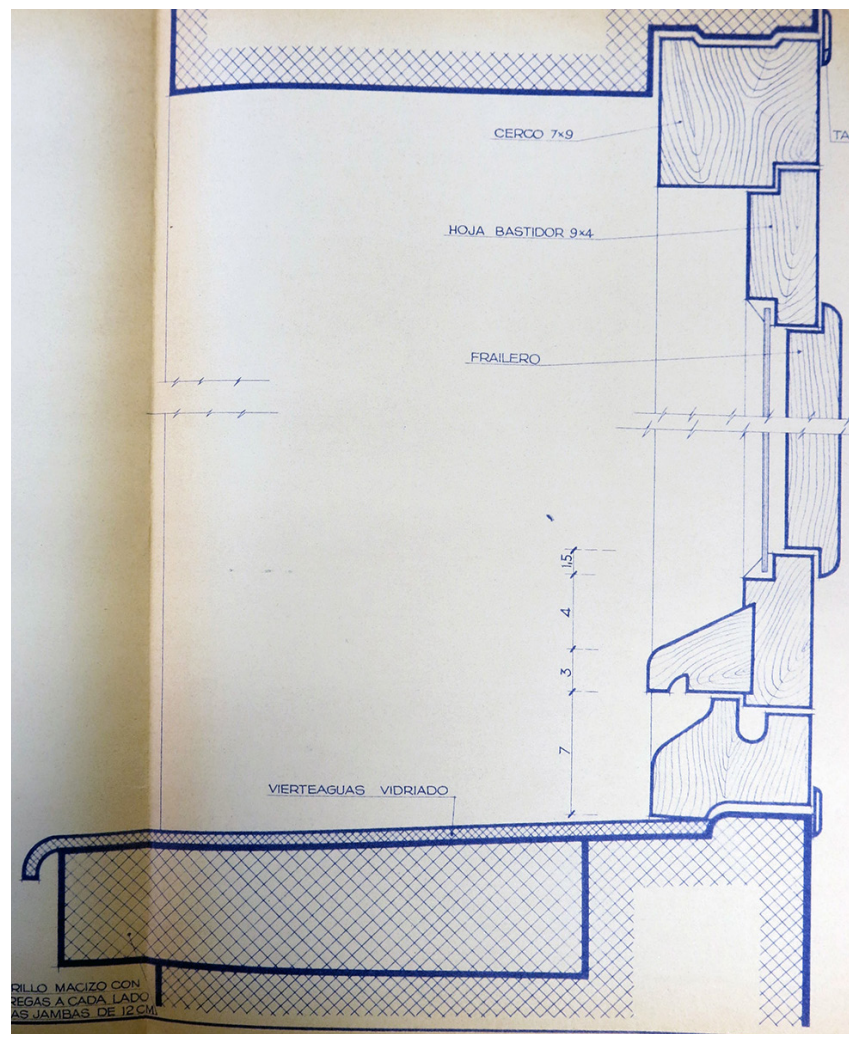

Figura 15. Detalle de carpintería en el grupo de viviendas RENFE de Cuatro Caminos-manzana Q (Madrid). AMF, proyecto M-972-RL (1955).

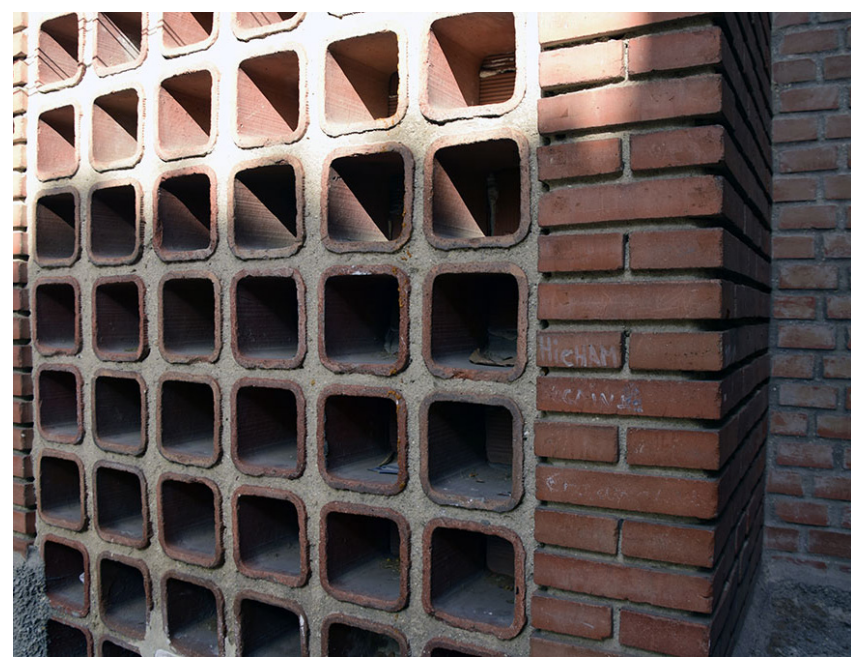

Figura 16. Pieza de celosía de grupo de viviendas RENFE en Villaverde Bajo. Fotografía de los autores (agosto, 2018). 


\section{CONCLUSIONES}

La construcción de vivienda ferroviaria supone una muestra representativa de la vivienda social edificada durante el franquismo, tanto por su volumen como por la impronta ideológica del Régimen, en lo relativo al ideal de vivienda para las clases trabajadoras y sus familias, que se desprende del análisis realizado. Este proceso se desarrolló a través de una empresa pública, la mayor del país en esos momentos, como RENFE que atendía a un sector estratégico, y luego tuvo su continuidad en las cooperativas tuteladas por la propia empresa.

La rigidez normativa básicamente enfocada a solventar mínimos higienistas y a la reducción de costes así como la ambigüedad, escasez o ausencia de prescripciones técnicas condiciona tipologías y soluciones constructivas que se perpetúan en el tiempo como nuevos estándares. En los casos analizados hasta el momento apenas se ha detectado evolución en las soluciones constructivas aplicadas, tanto en los proyectos de RENFE como en los de las cooperativas.

El análisis de estos proyectos nos permite conocer con detalle cuáles eran los materiales, y de qué modo se aplicaron técnicas y soluciones constructivas ya obsoletas en su mayor parte pero que, no sólo constituyen un patrimonio a analizar y conservar por tratarse, en algunos casos de técnicas de poca aplicación en la actualidad, sino porque se trata de un patrimonio en uso donde el análisis constructivo permite descubrir causas de patologías comunes y facilitar actuaciones de rehabilitación, a través de una adecuada interpretación.

La repetición de soluciones constructivas, con predominio casi absoluto de la cerámica y la ausencia casi total de prefabricación es otra de las principales características encontradas. No se detecta variedad de elementos constructivos o introducción de mejoras a pesar del "pacto americano" y la progresiva apertura a los mercados internacionales (1953) o del cambio de conciencia respecto de la vivienda social que tuvo lugar en 1954. Es lógico pensar que al tratarse de viviendas de un único promotor público del Régimen destinadas a un colectivo único se generara una homogeneidad, repetición de proyectos y soluciones constructivas, en este caso anacrónicas y de mínima calidad. Las celosías de las viviendas de Villaverde bajo (Madrid) suponen el único caso analizado hasta el momento de producto industrializado de diseño intencionado.

Se observan en las viviendas ferroviarias construidas en este periodo las consecuencias de la autarquía, incluso una década después de su finalización. Así, identificamos dificultad de acceso, escasez de materiales y repetición de soluciones constructivas con predominio casi absoluto del material cerámico. Consecuencia de esto es la perpetuación de los muros portantes de fábrica en edificios en altura contra toda lógica constructiva a pesar de la más que probada experiencia en el uso de estructuras reticulares de hormigón armado o perfiles de acero normalizado.

El análisis constructivo realizado muestra una serie de soluciones de difícil adaptabilidad a las nuevas exigencias de confort y sostenibilidad actuales. Es decir, a pesar de que son viviendas que continúan en uso y que, en muchos casos se ubican en localizaciones privilegiadas de la ciudad, como Delicias, Embajadores o Cuatro Caminos en Madrid, o Diagonal en Barcelona, o San Bernardo en Sevilla, requieren de complejas y onerosas actuaciones de rehabilitación que ponen en peligro su sostenibilidad.

El estudio, tanto del contexto normativo como del contenido de los proyectos, nos permite conocer la situación de una buena parte del parque de viviendas sociales de nuestro país, inmuebles de escaso porte, baja calidad en la construcción y demás elementos propios de la construcción seriada. A pesar de esto, son muestra de un momento singular, cuando se configura el nuevo modelo de acceso a la vivienda para las clases más modestas, circunstancia que le aporta un valor patrimonial singular y nos obliga a su documentación y registro.

\section{REFERENCIAS}

(1) Capel, H. (1990). Capitalismo y Morfología urbana en España. $1^{a}$ edición 1975. Barcelona: Círculo de Lectores.

(2) Tafunell, X. (2005). Urbanización y vivienda. En A. Carreras y X. Tafunell (Coord.), Estadísticas históricas de España, siglos $X I X-X X$ (pp. 455-499). Madrid: Fundación BBVA.

(3) Ley de 19 de abril de 1939, estableciendo un régimen de protección a la vivienda de renta reducida y creando un Instituto Nacional de la Vivienda, encargado de su aplicación. Boletín Oficial del Estado (BOE), nº 110, 20 de abril de 1939, pp. 2190-2198.

(4) Ley de 15 de julio de 1954 sobre protección de "viviendas de renta limitada", en BOE, nº 197, 16 de julio de 1954 , pp. 4834-4841.

(5) Valenzuela Rubio, M. (1977). La empresa industrial como promotor inmobiliario. En Ciudad e Industria. IV Coloquio sobre Geografía (pp. 211-227). Oviedo: Asociación Española para el Progreso de la Ciencias.

(6) Llordén Miñambres, M. (2003). La política de vivienda del régimen franquista: nacimiento y despegue de los grandes constructores y promotores inmobiliarios en España, 1939-1960. En G. Sánchez Recio y J. Tascón (Coord.), Los empresarios de Franco. Política y economía en España, 1936-1957 (pp. 145-169). Barcelona: Crítica.

(7) Cuéllar, D. y Martínez-Corral, A. (2018). Una casa para nuestros padres: una aproximación a las cooperativas de viviendas en España (1960-1985). En IV Congresso Internacional sobre Património Industrial. Cidades e Património Industrial. Aveiro, Portugal: APPI.

(8) Decreto por el que se concede a cada uno de los Organismos que constituyen la Red Nacional de los Ferrocarriles Españoles y la Explotación de los Ferrocarriles por el Estado la consideración de "Entidades Constructoras", a los efectos de viviendas protegidas. BOE, ${ }^{\circ} 128$, de 7 de mayo de 1944, p. 3575-3576.

(9) Santos, L. (2011). Urbanismo y ferrocarril. La construcción del espacio ferroviario en las ciudades medias españolas (pp. 44-86). Madrid: Fundación de los Ferrocarriles Españoles. 
(10) Ordenanzas Técnicas y Normas Constructivas por Orden Ministerial de 12 de julio de 1955, BOE, nº 197 de 16 de julio de 1955 .

(11) Reglamento sobre las restricciones de hierro en la edificación. BOE, $\mathrm{n}^{\mathrm{0}}$ 214, de 2 de agosto de 1941, pp. 5848-5853.

(12) Orden de 29 de febrero de 1944, por la que se determinan las condiciones higiénicas mínimas que han de reunir las viviendas. BOE, no 61, de 1 de marzo de 1944, pp. 1833-1834.

(13) Jordá, C. (2007). Hacia la modernidad técnica. En Vivienda moderna en la Comunitat Valenciana (pp. 14-28). Valencia: COACV.

(14) Paricio Ansuátegui, I. (1973). Las razones de la forma de la vivienda masiva. Cuadernos de arquitectura y urbanismo, 96: 2-18.

(15) Orden de 24 de noviembre de 1976 por la que se aprueban las Normas Técnicas de Diseño y Calidad de las Viviendas Sociales. BOE, $\mathrm{n}^{0}$ 296, de 10 de diciembre de 1976, pp. 24605 -24613 y modificadas en el BOE $\mathrm{n}^{0} 141$, de 14 de junio de 1977, pp. 13305-13329.

(16) Ros García, J. M. (2015). Factores de progreso en la vivienda subvencionada madrileña de los años cincuenta. Reseña histórica y normativa. Revista RITA (4), 102-109. Recuperado de https://dialnet.unirioja.es/descarga/articulo/5297097.pdf

(17) Azpilicueta, E., Araujo, R. (2012). El mito industrial. Revista Tectónica, 38 (julio): 4-19.

(18) Presa Santos, J. L. (1972). La prefabricación de la construcción. Revista de Obras Públicas, 119: 307-310.

(19) Lahuerta, J. (1965). Situación actual de la edificación en España. Arquitectura, 79 (julio): 48.

(20) Memoria proyecto Algodor. AMF, expediente M-5933-VP.

(21) Moya, L. (1943). Casas abovedadas en el barrio de Usera. Construida por la Dirección General de Arquitectura. Revista Nacional de Arquitectura, 14: 52.

(22) Moya, L. (1947). Bóvedas tabicadas. Madrid: Dirección General de Arquitectura.

(23) Ros García, J. M. (2005). La fábrica de doble hoja en Madrid, un siglo de cerramiento moderno. Informes de la Construcción, 56 (495): 57-71. https://doi.org/10.3989/ic.2005.v57.i495.455 